\title{
Trubarjev gmajn jezik kot osnova za prvo slovensko knjižno normo
}

\author{
Marko JeSEnŠEK \\ Univerza v Mariboru, Filozofska fakulteta, Koroška cesta 160, \\ SI-2000 Maribor,marko.jesensek@uni-mb.si
}

\begin{abstract}
Osnova za knjižni gmajn jezik je živa govorica, ki jo je Trubar poznal iz dolenjskih krajev, nadgradil pa jo je z gorenjščino in ljubljanskim govorom. Gmajn jezik je sopomenka za kranjski jezik, ki je prepoznaven po splošni razumljivosti, hkrati pa gre za jezikovni kompromis, tj. skupni imenovalec osrednjeslovenskega knjižnega jezika.
\end{abstract}

"Gmajn" literary language is based on the spoken language, which was familiar to Trubar from the Lower Carniola region. However, he upgraded it with Upper Carniolan, and with the language spoken in Ljubljana. "Gmajn" language is a synonym for Carniolan Language (kranjski jezik) which is known as being universally comprehensible. At the same time, "Gmajn" language is a language compromise for the Central Slovene Standard Language.

Ključne besede: Primož Trubar, gmajn jezik, krajnski jezik, osrednjeslovenski knjižni jezik, slovenska protestantska misel o jeziku

Key words: Primož Trubar, "gmajn” Literary Language, Carniolan Language, Central Slovene Standard Language, Slovene Protestants' Views on Language

0 Trubar je vedel, da slovenščine 16. stoletja, ki skoraj ni imela pisne tradicije, nič pa tiskov, ne more primerjati z nemščino, se je pa zavedal, da sta čas in prostor naklonjena veliki ideji, ki jo je lahko za Slovence takrat uresniči le on. Dalmatin je o tem leta 1884 v nemškem uvodu v Biblijo zapisal:

Bog pa nam je v tej deželi iz posebne dobrote in milosti pokazal s častitim in v Bogu učenim Primožem Trubarjem, rojenim Slovencom in izvoljenim orodjem, da se da tudi ta jezik z latinskimi črkami primerno in prav tako dobro pisati kakor drugi. 
1 Trubar v čudeže ni verjel, zato je potrebno poiskati prave vzroke za njegov gmajn jezik, ki se je zgodil v 16. stoletju.

1.1 Sam je zapisal: »Jest sem le-te bukvice pustil predrukati vsem slovenskim lubim otročičom h dobrimu, de se tudi iz nih brati inu ta celi hatehizmus navuče» (Abecednik 1566).

»Čudež« s slovenskim jezikom se ni zgodil čez noč, a ko se je, je bil sam po sebi umeven - Trubar je najprej izdal katekizem, tj. glavne nauke nove vere, in abecednik, tj. knjižico, ki bo naučila ljudi brati in pisati, da bodo $\mathrm{v}$ slovenskem jeziku lahko sami spoznali pravo vero. »Čudež« torej, ki so ga nekateri raziskovalci Trubarjevega življenja in dela kar malce preveč romantično pripisovali njegovi »ljubezni do svojega ljudstva in verski gorečnosti« (Rupel, 1962). Gorečnost in ljubezen sta imela pri Trubarju trden temelj, njegov načrt je bil jasen in premišljen: ponuditi pravi evangelij v knjigi, ki bo Slovence osredinila ob prvem knjižnem jeziku in Ljubljani kot njihovem najpomembnejšem kulturno-političnem in cerkveno-upravnem središču. Trubar je z iskanjem zahtevnejšega slovenskega cerkvenega knjižnega izrazila začel vzpostavljati gmajn jezik kot prvo osrednjeslovensko knjižno normo, izhajajočo iz želje po uveljavitvi slovenskega jezika pri razlagi verskih resnic. Prvič se je tako pojavilo pomembno spoznanje, da smo Slovenci kulturno in kot narod živi le, če lahko pišemo, tiskamo in beremo knjige $\mathrm{v}$ svojem knjižnem jeziku:

I.../ berite sami tu sv. Pismu, suseb Janža evangeli, tu djanje tih jogrov, s. Pavla listi, potle tiga s. rajha vero, od mene iztolmačeno, suseb predgovor. V tih boste nešli, de Kristus sam inu preroki, jogri drugiga nesu vučili, temuč kar mi zdaj vučimo inu verujemo, tu je, vse tu, kar je kratku v ti mali bibliji, v tim katehizmi zapopadeno. (Ta celi psalter Davidov, 1566).

Ljubezen do svojega ubogega, preprostega in dobrosrčnega slovenskega ljudstva in oznanjanje prave vere sta bila pri Trubarju povezana in sta nakazovala njegovo podzavestno razumevanje osrednjeslovenske knjižne norme, predvsem jezika v cerkvi in (verske) kulturnosti oz. kulture knjižne besede med Slovenci v 16. stoletju. Takole ju je sam nedvoumno in vzročno povezal:

\footnotetext{
Bog ve, da sem že v tistem času, ko sem že pri vas Slovencih pridigal iz latinskih in nemških knjig, pogosto vzdignil in vzkliknil k Bogu, naj se zaradi posvečenja svojega imena in razširjenja svojega kraljestva milostno ozre na našo ubogo, preprosto in dobrosrčno slovensko ljudstvo, naj mu prizanese in ga obdari z veliko milostjo in darom, da bi se kakor jezik drugih narodov tudi njegov jezik pisal in bral in da bi se sveto pismo in druge dobre krščanske knjige prav prevedle in natisnile $v$ slovenskem jeziku.
}

2 Trubarjeva odločitev za gmajn jezik je bila, če se izrazim moderno, projektno delo. Trubar je imel natančen načrt, kaj misli narediti na področju vere in kulture in kako bo to uresničil. 
2.1 Osnutek tega projekta je izhajal iz reformatorskega koncepta, po katerem je kot stranski produkt pa vendar skoraj samoumevno nastal jasen načrt t. i. osrednjeslovenskega knjižnega jezika (Rajhman, 1977).

2.2 Pravnost za gmajn jezik je Trubar našel v Pismu Rimljanov: »Kajti pisano je: Kakor živim, pravi Gospod, se bo pred mano upognilo vsako koleno in vsak jezik bo slavil Boga« (Rim, 14,11). To svetopisemsko mesto je bilo za Trubarja dovolj trden temelj (če lahko tako rečem, zavedajoč se, da je njegova razlaga večplastna), da je v nemškem posvetilu prevoda $\mathrm{z}$ naslovom Ta prvi dejl tiga noviga testamenta (1557) lahko zagovarjal svojo odločitev za prevajanje cerkvenega besedila v osrednjeslovenski jezik:

Sv. Pavel prišteva tudi raznovrstne jezike med darove sv. Duha, a Bog mi je iz posebne milosti zaradi Jezusa Kristusa naklonil znanje slovenskega jezika, kakor ga govore v naši deželi Kranjski, pa sem v njem pridigal, kakor veste, sedemnajst let v raznih krajih slovenskih dežel; razumem tudi precej latinsko, nemško in laško. To torej in moja vest sta me gnala k temu prevajanju. In ker zdaj tudi nikogar ni, ki bi se hotel tega dela lotiti, sem se tedaj v imenu Gospodovem drznil in začel na najlažjem mestu.

2.3 To »najlažje mesto« je bilo rojstvo osrednjeslovenskega knjižnega jezika, Trubarjevega gmajn jezika, oz. od Krelja imenovanega tudi gospod Trubarjeva kranjščina. V nemškem uvodu leta 1557 je Trubar preprosto zapisal, da je bilo vse samo po sebi umevno, da se je to moralo zgoditi, da je bila to naravna pot nastanka osrednjeslovenskega knjižnega jezika. V praksi pa je bilo čisto drugače, veliko težje, kot se zdi iz Trubarjeve skromne izjave, da je začel na najlažjem mestu. Šlo je za premišljeno odločitev, za prvi slovenski jezikovni koncept - najlažje mesto je od Trubarja zahtevalo, da je določil knjižno normo, osnovo za to normo in pisavo. Kako dolgo in kako je o tem razmišljal, ne vemo - lahko je to navdušenje za slovenski jezik prišlo samo od sebe, lahko (in to je bolj verjetno) je imelo daljšo predzgodovino. Danes je težko natančno določiti, kolik je bil pri tem npr. neposredni vpliv škofa Bonoma, tržaških izkušenj in/ali takratnih političnih razmer v evropski cerkvi; burno obdobje (pred)reformacije na Slovenskem je Trubarja odločilno zaznamovalo in čeprav je dolgo okleval med katolištvom in reformatorstvom, je že leta 1550 pokazal, da o knjižnojezikovni avtonomnosti Slovencev nikoli ni dvomil. Že pred izidom prvih slovenskih tiskanih knjig je vsa svoja prizadevanja, želje in pričakovanja podredil praktični uporabnosti in koristnosti osrednje slovenščine: bilo je jasno, da je središčni jezikovni koncept najprimernejši - izkušnja iz Trsta in prvega službenega mesta na Štajerskem ga je samo še potrjevala, da se je zaradi splošne razumljivosti potrebno previdno dvigniti nad dialekt.

2.3.1 Osnovo za knjižni jezik je Trubar naravno prepoznaval v živem, govorjenem jeziku. Nič umetnega ni mogel dodati gmajn jeziku, ki je Slovencem v osredju že pred Trubarjem omogočal praktično sporazumevanje med preprostimi ljudmi. Odločil se je za živo govorico, ki jo je poznal iz dolenjskih krajev, nadgrajeno z gorenjščino in ljubljanskim govorom. Tako je oblikoval sinhroni jezikovni koncept, prvo nadnarečno osrednjeslovensko knjižno nor- 
mo, ki je bila po njegovem mnenju splošno razumljiva $v$ najširšem slovenskem jezikovnem prostoru. Trubar je v nemškem posvetilu k že omenjenemu prevodu (Ta prvi dejl tiga noviga testamenta, 1557) zelo jasno zapisal, da je zavestno iskal delni sporazum, skupni imenovalec slovenščine, v takrat že prepoznavno izoblikovanem slovenskem narečnem jezikovnem prostoru. Trubarjev gmajn jezik ni do potankosti določen in premišljen sistem, ampak uporabno orodje za razumljivo sporazumevanje. Prav ta splošna razumljivost je prepoznavna podoba Trubarjevega koncepta gmajn jezika:

Pri prevodu sem se potrudil glede besede in sloga, da bi ga utegnil z lahkoto razumeti vsak Slovenec, bodisi Kranjec, Spodnještajerec, Korošec, Kraševec, Istran, Dolenjec ali Bezjak. Zaradi tega sem ostal kar pri kmečkem slovenskem jeziku, kakor se govori na Raščici, kjer sem se rodil. Nenavadnih in hrvaških besed nisem hotel primešavati, niti si novih izmišljati. I.../ Če sem pa nekatere besede nenatančno prevedel, se je zgodilo, zaradi pomanjkanja slovenskih besed, ali pa zato, ker jih nisem poznal oz. mi takrat niso prišle na misel. (Citirano po: Glavan, 81)

3 Trubarjeva odločitev za gmajn jezik izhaja iz njegovega prepričanja, da mora tudi knjižna norma upoštevati načelo preprostosti. Verske resnice se lahko razlagajo, povedo na preprost in razumljiv način tudi v slovenskem jeziku, saj je odklanjal takrat splošno misel o robatosti slovenskega jezika. Zavedal se je narečne razcepljenosti slovenščine, želja o takem jeziku, ki bi ga utegnil z lahkoto razumeti vsak Slovenec, pa ga je vodila do razmišljanj, česa se je potrebno držati v knjižnem jeziku. Jezikovni predpis, ki ga je Trubar zagovarjal, je izhajal iz njegovega razumevanja rabe gmajn jezika - ta besedna zveza tudi najbolje določa Trubarjev jezikovni program, ki se kaže v odločitvi za nadnarečni sinhroni osrednjeslovenski jezikovni koncept in bohoričico kot primerno pisavo za tak knjižni jezik.

3.1 Trubar je v 16. stoletju združil v osrednji knjižni jezik, ali kot ga je sam imenoval kranjski jezik, do takrat že razdruženi osrednjeslovenski narečni prostor z Ljubljano kot naravnim geografskim in kulturnim središčem, oz. s takrat nastajajočim povezovalnim mestnim ljubljanskim govorom (pridigarska tradicija in slovensko predknjižno izročilo). Verjetno je $\mathrm{v}$ tem jeziku prepoznaval tudi narodotvorno vlogo, saj je t. i. kranjsko narečje razumel kot povezovalni jezik tistih slovenskih pokrajin, ki jim je namenil katekizem in abecednik. $L u b i$ Slovenci, preprost slovenski narod, so bili v 16. stoletju čisto slovenski najbrž le na Kranjskem. »Slovenci« so mu bili Kranjci, Korošci, Štajerci, Dolenjci, Krašovci, Istrijani in Bezjaki; in ker so v 16. stoletju kajkavci svoj knjižni jezi imenovali slovenski, se zdi, da je Trubar v Urachu kratek čas celo razmišljal o tem, da bi k osrednejslovenskemu (kranjskemu) knjižnemu jeziku pritegnil tudi hrvaške kajkavce: »Te ene besede, koker krščenik-kristjan, Jezus je v grob položen-Jezus je pokopan, Sloveni in Krovati tolmačijo; na tim se nema oben zmotiti, zakaj obuje je prav.«

Zanimivo je, da tako nikoli ni razmišljal o Prekmurcih, ki jih npr. leta 1566 v nemškem uvodu v Ta celi psalter Davidov niti ni naštel med »Slovenci«: 
Blagorodnim, plemenitim /.../ meščanom in vsem pobožnim kristjanom, ki prebivajo $v$ kneževini Kranjski, Spodnještajerski in Koroški, v grofiji Goriški, v Slovenski marki, v Metliki, na Krasu in v Istri, pristašem augsburške veroizpovedi. (Citirano po: Glavan, 126).

Nanje se je skliceval šele leta 1882 v nemškem uvodu k delu Ta celi novi testament, kjer je dosledno razlikoval med slovenskim in ogrskim jezikom gmajn jezik je osrednjeslovenski in panonske slovenščine v ta okvir ni pritegnil:

Mi Kranjci, Spodnještajerci, Korošci in Slovenci, ki z navadnim kmečkim ljudstvom uporabljamo slovenski jezik, moremo in moramo po pravici /.../ zahvaliti in slaviti Boga za milost, ki nam jo je dal v Jezusu Kristusu, da smo po njem vsestransko obogateli v vsakršnem smislu in spoznanju /.../ Zakaj nam in vsakomur je znano, da ni bilo najti pred štiriintridesetimi leti nobenega pisma ne registra, nikar knjige $v$ našem slovenskem jeziku, ker so menili, da sta slovenski in ogrski jezik tako surova in barbarska, da se ne dasta ne pisati ne brati.

Trubarju se je zdelo, »da tih drugih dežel ludi tudi mogo zastopiti«, zato je sklenil, »delu v ta kranski jezik ... postaviti.« Izraz kranjski jezik je pri Trubarju stilna sopomenka za gmajn jezik, tj. metafora za preprost jezik kmetov, ki opirajoč se na predknjižno izročilo prerašča $\mathrm{v}$ preprost osrednjeslovenski knjižni (cerkveni) jezik, ki se, tako poudarja Trubar sam, izogiba »obračanu oli tolmačenu lepih, gladkih, visokih, kunštnih, novih oli neznanih besed, katerih vsaki dobri preprosti Slovenec lahku more zastopiti«. Gmajn jezik je torej zavestno preprost nadnarečni kranjski jezik, tj. živi govor, ki izhaja iz dolenjščine, gorenjščine in ljubljanskega govora. Trubar je središčni jezik, naddialekt, postavil za osnovo svojemu knjižnemu gmajn jeziku.

3.2 Taka odločitev za preprost jezik seveda ni zavračala strokovnih izrazov tam, kjer jih je potreboval. Terminologija je pomenila odmik od prvotnega jezikovnega programa, od t. i. gmajn jezika, in kaže, kako je Trubar pilil jezik in iskal primerne rešitve - pri tem prihaja do izraza jezikovna omikanost in primernost jezikovnih sredstev (zlasti besedja) v njegovih prevodih, ko je zaradi boljše razumljivosti dodatno razlagal novotvorbe ter iskal tudi tujejezične sopomenke in ustreznice »To latinsko besedo lex Nembci imenujejo Gesetz, t $i$ Krovati inu Peami Zakon, mi Kranjnci pak po tej nembščini nji pravimo Postava ...; koker Nembci tolmačimo Gnada, Krovati in Peami milost.«

3.3 Zadrego s pisavo je rešil v dveh korakih: (1) najprej je leta 1550 priredil gotico slovenskim glasoslovnim posebnostim, nato (2) pa je leta 1555 uvedel latinico. Postopnost pri uvajanju ustrezne samostojne »slovenske« pisave je razlagal tako, da je hotel »po tej ortografiji štaltnu ino zastopnu pisati«. Nekateri črkopisi (npr. češki, poljski ...) so mu bili »grdi viditi«, ker ni želel "preveliku puhštabov oli konzonatov $k$ ani silabi jemati«, grška pisava pa zanj ni bila sprejemljiva, ker je želel »zastupno« pistati« (ptujski minorit Penn se je sredi 19. stoletja zanjo vendar odločil kot za nevtralno, začasno in nadomestno rešitev v slovenskem črkarskem sporu). Latinica, ki jo je uvedel leta 1550, »de ta beseda s tejmi latinskimi puhštabi se lepši inu ležej piše ter bere«, je kljub 
slovenskim dvočrkjem ostala prepoznavno nemška. Trubarjeva reforma pisave ni bila tako posrečena in premišljena kot njegova jezikovna norma. Dela se je lotil premalo natančno, verjetno se mu vprašanje pisave ob prevajanju in normiranju jezika ni zdelo tako pomembno, predvsem pa je zmotno pričakoval, da bodo bralci slovenskih knjig sami našli »ključ za izgovor slovenskih besed $v$ nemško-latinskem pismu po načinu in lastnostih našega jezika«. Gre za opazno nedoslednost $\mathrm{v}$ njegovem jezikovnem programu, saj je pri osnovi za osrednjo knjižno slovenščino izhajal iz gmajn jezika, pri črkopisu pa je računal na t. i. izobraženega bralca, ki zna celo nemško ali latinsko. Temeljno načelo njegove norme, tj. splošna razumljivost, pa s tem vendar ni bila ogrožena - Trubar se nikoli ni strinjal z, tako je tudi sam zapisal, »umestnimi rešitvami« Krelja in Bohoriča. Merilo izrazne uspešnosti mu je bila vedno živa ljudska govorica in glede besedja se je dosledno odločal za izraze, ki so bili živi med ljudmi, tudi če je šlo za prevzete besede. Taki izrazi, ki nikoli niso prestopili v žargon, pa dajejo Trubarjevemu gmajn jeziku prepoznavno podobo živosti in razumljivosti, upoštevajoč predvsem jezik Ljubljane. Trubarjev gmajn jezik kot podlaga za osrednjeslovenski knjižni jezik je torej živ pridigarski jezik 16. stoletja z bogato izrabo sopomenskosti (domači izrazi, sposojenke in tujke), vendar hkrati navezan tudi na ustno slovensko pridigarsko tradicijo.

3.4 Trubar se je zavedal svoje vloge pri oblikovanju slovenskega knjižnega jezika. Leta 1561 je v edini knjigi, ki jo je izdal samo v nemščini (Register und summarischer Inhalt), o svojem prevajanju v slovenščino zapisal: »Odkar svet stoji, se to nikdar ni zgodilo, zakaj slovenski jezik se doslej nikoli ni pisal, še manj pa tiskal.« (Citirano po: Glavan, 81).

Zapis dokazuje, da Brižinskih spomenikov v 16. stoletju niso poznali, prav tako ne Rateškega rokopisa in drugih jezikovnih drobcev, vprašanje pa je, zakaj je Trubar »zatajil« Stiški rokopis in (verjetno) tudi slovenski jezikovni drobec na nemškem sramotilnem letaku iz leta 1515.

4 Trubarjevo odločitev za gmajn jezik je v 16. stoletju prevrednotil Kreljev koncept slovenskega jezika. Soočila sta se dva različna jezikovna pogleda, sinhronija in diahronija, ki sta nato v zgodovinskem razvoju slovenskega jezika določala različni knjižni normi in predpisa na Slovenskem.

Knjižni status slovenskega jezika v 16. stoletju je odločilno zaznamoval Jurij Dalmatin, ki je s pravim jezikovnim čutom in odločitvijo za sredinskost združil Trubarjev in Kreljev pogled na jezik (Orožen, 1996, 1996a) ter s prevodom Biblije (1584) določil ustrezno normo za slovenski jezik - njegova Biblija ni bila le temeljna knjiga krščanstva na Slovenskem, filozofsko in umetnostno besedilo ali največji tiskarski dosežek na Slovenskem, ampak tudi jezikovni priročnik za vse pišoče Slovence naslednjih dvesto let. To se je zgodilo zato, ker je Dalmatin znal odbrati vse dobro iz Trubarjevega gmajn jezika in s posluhom sprejeti tudi Kreljeve reforme (Orožen, 1996b) ter tako pokazati, da je jezik sicer samobiten, vendar pa ne izhaja sam iz sebe, ampak iz človeka, ki ga uporablja, nanj vpliva in duhovno določa. Samobitnost slovenskega knjižnega jezika je po 16. stoletju prišla najbolj do izraza takrat, ko so njegovi vodniki 
in uporabniki sledili Dalmatinovi sredinskosti. Pozitivna razvojna pot je pripeljala do združitve osrednje- in vzhodnoslovenskega knjižnega jezika sredi 19. stoletja in oblikovanja t. i. novoslovenščine ter Škrabčeve odločitve, da je 16. stoletje meja, ki se je pri določanju normativnosti slovenskega jezika ne sme prestopiti. Škrabčevo jezikoslovje tako združuje vse sprejemljive diahrone in sinhrone poglede na slovenski jezik od 16. stoletja naprej, jezikovne skrajnosti pa so se dogajale na obrobjih, ko je pretirano zavzemanje za "gmajn jezik» pripeljalo do vdora narečnih elementov v knjižni jezik (pridigarstvo baroka in razsvetljenstva) in oblikovanja pokrajinskih knjižnih različic (vzhodnoštajerski knjižni jezik in Dajnko), na drugi strani pa je nekritično upoštevanje diahronih jezikovnih pogledov pripeljalo do jezikovnih zablod (ilirizem, slavizacija in arhaizacija jezika, levstikovanje).

V zgodovinskem razvoju slovenskega jezika se je pokazalo, da je bila Trubarjeva odločitev za gmajn jezik z nekaterimi Kreljevimi dopolnitvami in Dalmatinovo sredinskostjo prava odločitev in dobra osnova za prvo (osrednje) slovensko knjižno normo - Škrabec je to konec 19. stoletja potrdil na najboljši možni način.

5 Trubarjev koncept gmajn jezika se kaže tudi kot možno izhodišče za razmišljanje o njegovem »literarnem programu«, in sicer o vlogi in pomenu cerkvenega slovstva za Slovence v 16. stoletju:

Mi nočemo prevajati ne tiskati nobene prepirljive, nepotrebne ali močno izpodbitne knjige, ampak zgolj to, kar potrebuje ubogi, navadni, preprosti človek za zveličanje svoje duše /.../, kar moremo lahko zagovarjati pred vsem krščanstvom in dokazati z jasnimi izreki iz sv. pisma in iz katekizma.

Trubar se je odločno zavzel za cerkev slovenskega jezika in cerkveno slovstvo v slovenskem jeziku:

Ampak kedar se v ti cerkvi s tejm zastopnim gmajn deželskim jezikom bere, poje inu pridiguje, taku od tiga ta cerkov, tu je ta gmajna vseh vernih, bo v ti veri potrjena ... Za tiga volo je veliku nucniša ena kratka, zastopna pridiga, koker deset tavžent nezastopnih maš. (Svetiga Pavla ta dva listi h tim Korintarjem inu ta h tim Galatarjem, 1561. Citirano po: Glavan, 98).

Za Trubarja so bili širjenje krščanske (prave) vere in načeli praktične uporabnosti ter koristnosti na prvem mestu. Toda ta program je imel ob sebi nujen, obvezen, neizogiben »stranski produkt«, tj. oblikovanje slovenskega knjižnega jezika:

Vas vseh v tim božjim imenu zvejstu prosim inu opominam, de vi nerpoprej visoku zahvalite Boga za le-to dobrutu inu za ta velik dar božji, kir se taku zdaj /.../ ta naš jezik tudi piše in druka.

Utilitarna literatura je bila po Trubarju možna le v razumljivem, preprostem, gmajn jeziku: »Vse riči v cerkvi, pridige, molitve inu petje, se ima v tim gmajn 
zastopnim jeziku vsake dežele dopernesti.« Jezik liturgije in šolstva mora biti zato slovenščina:

Vsem zastopnim krščenikom je vejdeč, de ti psalmi inu druge duhovne peismi se imajo v ti cerkvi pejti; ampak kir so se dosihmal le v latinskim, tim gmajn ludem v nezastopnim jeziku v ti cerkvi pejli inu tudi mašovali, krščovali inu brali le latinsku, tu mi držimo za nepridnu inu unucnu; inu kir so s takim latinskim petjem inu branem tudi hoteli milost, odpuščane tih grehov inu druge riči per Bugi dobiti inu zaslužiti, le-tu mi držimo za enu pregrešene inu zašpotovane te kriji Kristusove. Obtu mi hočmo, de uže naprej v ti naši kranjski deželi, de se ti psalmi, pejsmi inu vse druge službe božje, ti sv. Zakramenti v tim slovenskim kranskim jeziku dopernašajo inu dile. (Cerkovna ordninga, 1564. Citirano po: Glavan, 118).

Inu de ti hlapčiči inu deklice vsako nedelo ob puldnevi oli ob večernici zred s tejmi farmani v to cerkov prido inu tak katekizmus, koker je le-tukaj zapisan, vprašajo inu odgovarajoč očitu inu zastopnu izvuna gori povedo. (Cerkovna ordninga, 1564. Citirano po: Glavan, 118).

6 Trubarjev gmaj jezik se je pripravljal najprej na prižnici, izhajajoč iz živega govora slovenskega alpskega jezikovnega prostora in osrednjeslovenske pridigarske tradicije, vendar brez poznavanja jezika Brižinskih spomenikov in drugih zapisanih predknjižnih izročil (razen izrazito dolenjsko obarvanega Stiškega rokopisa). Trubar je pri tem izhajal iz reformatorskega koncepta, po katerem je skoraj samoumevno nastala jasna zasnova t. i. osrednjeslovenskega knjižnega jezika (od Krelja imenovanega tudi gospod Trubarjeva kranjšči$n a)$ - normiral ga je kot nadnarečno tvorbo središčnih slovenskih narečij, in sicer $\mathrm{z}$ večjim deležem dolenjščine kot gorenjščine in opazno vlogo takrat že nastajajoče ljubljanske mestne govorice. Trubar svojega gmajn jezika ni veliko spreminjal in je z malo dopolnitvami ostal enak petindvajset let, čeprav sta bila s Kreljem različnih pogledov:

Kar se pa tiče prevoda ali tolmačenja, sem pustil tale testament $v$ svojem prvotnem prevodu, zakaj pri ponovnem branju nisem našel v njem nič nepravilnega. Tudi me $v$ vseh 25-ih letih, odkar sem začel prevajati, nihče ni obdolžil česa krivega. (Ta celi novi testament, 1882, nemški uvod).

Trubarjeva jezikovna kultura je na zelo visoki ravni - njegovi prevodi, priredbe in samostojna besedila so jezikovno-stilno premišljeno izoblikovani v prerodnem duhu. Jezikovna omikanost opazno izstopa, tako da je njegov gmajn jezik upravičeno dobil veljavo modernega osrednjeslovenskega knjižnega jezika, ki nam že skoraj petsto let kaže vedno nove načine razmišljanja o jeziku in njegovem spreminjanju. 


\section{LITERATURA}

Kozma AHAČIČ, 2007: Zgodovina misli o jeziku in književnosti na Slovenskem: protestantizem. Ljubljana.

Mihael GLAVAN, 2008: Trubarjev album. Romanje s Trubarjem. Ljubljana.

France KIDRIČ, 1951: Primož Trubar. Ljubljana.

Majda MERŠE, 1990: Jezikovne spremembe v Trubarjevih prevodih Nove Zaveze. Razprave. Ljubljana, 163-179.

- -, 2005: Trubar v Škrabčevem jezikoslovju. Jezikoslovci in njihova dela v Škrabčevih očeh: Škrabčeva misel V: zborniks simpozija 2005. Nova Gorica, 49-69.

France NOVAK, 2000: Vloga protestantizma pri oblikovanju slovenskega knjižnega jezika. Protestantizem - zatočišče izgnanih na Petanjcih (Nádasdyjev dvorec). Petanjci, Ljubljana, 213-229.

Martina OROŽEN, 1996: Trubarjev jezikovni nazor in njegov knjižni koncept v obrednih besedilih. Poglavja iz zgodovine slovenskega knjižnega jezika. Ljubljana, $114-129$.

--, 1996a: Kreljev jezikovni koncept. Poglavja iz zgodovine slovenskega knjižnega jezika. Ljubljana, 170-187.

- -, 1996b: Slovnična in besediščna preobrazba Dalmatinovega knjižnega jezika ob Japljevem prevodu Biblije (1584-1784-1802). Poglavja iz zgodovine slovenskega knjižnega jezika. Ljubljana, 251-269.

Breda POGORELEC, 1984: Novi pogledi na slovenski knjižni jezik. Protestantismus bei den Slowenen - Protestantizem pri Slovencih. Wien, 181-208.

Jože RAJHMAN, 1977: Prva slovenska knjiga v luči teoloških, literarno-zgodovinskih, jezikovnih in zgodovinskih raziskav. Ljubljana.

- -, 1986: Pisma Primoža Trubarja. Ljubljana.

- -, 1986a: Trubarjev svet. Trst.

Jakob RIGLER, 1965: Osnove Trubarjevega jezika. JiS. 161-172.

- -, 1968: Začetki slovenskega knjižnega jezika. Ljubljana.

Mirko RUPEL, 1962: Primož Trubar: življenje in delo. Ljubljana.

Jože TOPORIŠIČ, 1992: Enciklopedija slovenskega jezika. Ljubljana.

\section{SUMMARY}

Trubar was the first author to translate New Testament for Slovenians into language understandable to them (the first fragments in Catechisms, followed by the Gospel of Matthew /1555/, Ta prvi dejl tiga novega testamenta (The First Part of This New Testament/ /1557/, Ta drugi dejl tiga novega testamenta /The Second Part of This 
New Testament//1560/, Novega testamenta poslednji dejl/The New Testament's Last Part/ /1577/, Ta celi novi testament /The Complete New Testament//1582/). By doing so, Trubar set the norms for the Central Slovene Standard Language (Carniolian). He recognized the Carniolian dialect to be a natural linkage between central Slovenes, yet he tried deliberately to be compatible with and to be understandable to as many "dear Slovenes" as possible. In the $16^{\text {th }}$ century, Trubar's plain language was limited mostly to church literature, but it started to make its way into the society of European languages very successfully although plain language was meant to be only a by-product of Protestantism at first in order to overtake the role of domestic language and a kind of methodological aid in the Church.

At first, Trubar's gmajn jezik (plain language) was preached from pulpits and it originated from the live speech of the Slovene Alpine linguistic area and from Central Slovene Standard Language preaching tradition; however, without knowing the Freising Manuscripts and other written pre-literary records (except the Stiški rokopis, strongly influenced by the Lower Carniolian dialect), Trubar proceeded from the reformatory concept according to which the concept of the so-called Central Slovene Standard Language (Krelj named it Mr. Trubar's Carniolian language) was actually a natural result. Trubar normed it as an over-dialectal formation of central Slovene dialects in which the Lower Carniolian dialect prevailed over the Upper Carniolian dialect and in which the language of Ljubljana city started to play an important role. Trubar's linguistic culture is on a very high level - his translations, adaptations and autonomous texts are linguistic-stylistically well considered and in a reformist spirit. Linguistic accomplishment is clearly distinguished by Trubar's use of communicational resources, in surpassing the Latin original, and in well recognized independence from German syntax. Accordingly, Trubar's "plain language" achieved the importance of modern Central Slovene Standard Language. 